\title{
Exploration on Teaching Reform of Biomass Processing and Utilization Curriculum in Agricultural Universities
}

\author{
Shusheng Wang* \\ College of Life Science \\ Jilin Agricultural University \\ Changchun, Jilin \\ E-mail: wangshusheng@jlau.edu.cn
}

\author{
Yuchun Su \\ College of Life Science \\ Jilin Agricultural University \\ Changchun, Jilin
}

\begin{abstract}
Biomass processing and utilization is a compulsory course for bioengineering major in Jilin Agricultural University. This paper studied on the reform of Biomass processing curriculum for bioengineering talents cultivation projects (2014), and investigated the effects of new curriculum on knowledge acceptance of students during talents training. The results revealed that the establishment of Biomass process and utilization curriculum in agricultural university, building of related teaching documents, and practice of computer-assisted instruction during teaching inspired the learning interests of the students of bioengineering major and achieved expected results in teaching program. Establishment and practice of biomass systematic course in Jilin Agricultural University improved the knowledge level of the students and broaden their employment fields.
\end{abstract} effects

Keywords_biomass; talent training; teaching reform; teaching

\section{INTRODUCTION}

Biomass generally refers to the natural polymer that produced by the photosynthesis of carbon dioxide as the raw material, which can be degraded into water and carbon dioxide by microorganisms or photo degradation in nature or reused as fertilizer after decomposed. The main chemical compositions of biomass are cellulose, hemicellulose, lignin and other natural organic complex. The biological structure of biomass is multicellular, the same as wood. By using woody plants, grain plants, vines, their processing residue and waste as raw material can obtained a series of high performance, multifunction and high value-added novel biomass composites. These composites could be technically produced via physical, chemical and biological process. The composites have multiapplication in daily life. Biomass composites have the advantages of biodegradability, recyclability, environmental friendliness, wide sources and renewability etc.

In recent years, along with the enhancement of consciousness for environmental protection, people gradually deepen the understanding of energy crisis and resource constraints. Therefore, to fabricate composites from plant fiber materials and manufacture biodegradable plastics with plant sources materials (alternatives for non-biodegradable plastic derived from petroleum resources) attracted great attention.

Research project of higher education reform in Jilin province "research on the reform of bioengineering specialty training mode in local agricultural colleges"
The preparation of environmentally friendly biomass composite gradually become the inevitable trend of composite materials, and was considered to be one of the most promising materials in 21st century. Biomass materials science is the fundamental for biomass utilization, and the premise for biomass materials processing. Research on biomass materials is a priority subject in the national program for medium- and long-term scientific and technological development (2006-2020) issued by the ministry of science and technology in 2006 [1-4]. Nowadays, governments all over the world are guiding by biological economy, insist on sustainable development strategy. Peoples started for the protection of natural resources and ecological environment, make full use of eco-friendly and renewable biomass resources, to replace increasingly exhausted non-renewable and polluting fossil materials. Furthermore, the utilization of biomass materials will alter the policy of using steel and plastic to replace wooden material for decades in China.

Starch products technology was one of the important courses for bioengineering major in Jilin Agricultural University. The main purpose was to cultivate technicians for biomass utilization industries. For more than ten years of teaching practice, this course introduced the fundamental principles of starch value-added processing comprehensively, and cultivated a large number of technical talents for enterprises of advanced corn processing. With the development of society, corn fine processing industry has reached its maximum of development, and the requirement for relevant technicians has basically reached saturation status. Graduates feedback illustrated that starch products technology and related courses were not meet the demanding for hunting a job in employment market, for the reason that course content limited the field. This promoted the teachers to re-consider the situation of students who are hunting for job in market, and adjust the course system of the major and choose suitable content for students.

Under such background, it was particularly important to set up a new series of courses named Biomass material processing and utilization for the students in the bioengineering major in agricultural colleges and universities, so as to broaden students' knowledge and offer more opportunities for job-hunting in future. By taking the opportunity of teaching course system 
revise in Jilin agricultural university, a new research direction for biological engineering major was established in order to develop a unique professional feature for the students. Furthermore, this project could transport specialized talents for industries in China; especially the manufactures majored in comprehensive utilization of biomass raw materials.

\section{ACHIEVEMENTS OF CURRICULUM REFORM}

With the rapid development of biological industry, the demand for bioengineering technicians increased. Furthermore, the required abilities for technicians reached higher levels that need the students to achieve innovative and comprehensive abilities. Hence the special training project was very necessary. In order to realize this goal of talent cultivation, teachers of bioengineering major effectively implemented teaching reform based on the aim of combining with the cultivation of innovative and comprehensive abilities for students, so as to provide innovative bioengineering talents to the society.

Teaching reform is an essential and important link in the development of higher education. With the deepening of undergraduate teaching reform in higher education institutions, various new teaching modes emerged, along with diversified teaching methods, more advanced teaching techniques and multiple teaching contents. But for ordinary agricultural colleges and universities, to keep up with the pace of the times and to do a great work in teaching reform is facing numerous difficulties.

In order to meet the needs of curriculum reform, teachers of bioengineering major founded a research team to explore the teaching reform of biomass processing and utilization. After years of hard work, the following results have been achieved:

\section{A. Research on the feature and orientation of Biomass processing and utilization courses}

According to the needs of social development, the founding of Biomass materials course in agricultural colleges and universities should focuses on highlighting the processing characteristics of materials and supplement the mastery of theoretical knowledge, hence students could understand the fields involved in biomass materials and the processing technology of various biomass materials, and improve their vocational skills. Through the research of teaching reform, the feature and orientation of Biomass materials courses series which meet the need of bioengineering specialty in agricultural colleges and universities were established, and the teaching syllabus was developed. Expected effects on course teaching were attained through practice procedure.

\section{B. Determine the training program of Biomass processing and utilization series courses}

After the reformation, we established a training program according with the characteristics of biological engineering curricula plan. The plan mainly included: name of course, teaching hours, character of course, objective targets (professional abilities, knowledge level, social and methods), curriculum content, training program, teaching plan, course assessment plan, teaching material, resources, etc.

\section{Determination of teaching contents and selection of teaching materials for the courses}

Base on the orientation for bioengineering talents training in agricultural colleges, and take advantage from the biomass related courses established in other colleges, we chose the Processing and utilization of biomass materials series books as main course teaching content for bioengineering major in Jilin Agricultural University. Then we selected the suitable teaching materials for students. Biomass materials processing and utilization, which was edited by Zhen-hua Gao and published in chemical industry press, was chosen as fundamental materials for the course. The other teaching materials included: Biomass materials processing and application (edited by Huang Jin, Chemical Industrial Press), Modern analysis technology of biomass materials (Di Mingwei as chief editor, published by Chemical Industrial Press), Biomass energy utilization technology (edited by Zhang Jian-an, published by chemical industry press).

\section{Editing multimedia course-software for the courses of Biomass processing and utilization}

In order to enhance the teaching effect of Biomass processing and utilization and stimulate students interest in learning, we decided to introduce multimedia courseware into teaching of the course. The courseware based on the book Biomass processing and utilization, edited by Gao Zhen-hua, and integrated other reference books. To broad the field, we expanded the content of the chapters, adjusted the proportion for the lecture. The purpose was to make sure the entire course system more scientific and reasonable. Expecting the teaching content become more integrity and more beneficial for the students. Then they would understand and accept the key point of the course more easily. Therefore, the teaching effect could be improved significantly. After a long time of hard work, the multimedia teaching courseware was produced. The coursesoftware including links, real pictures, FLASH animation, video image links and other content. The course media software was put in practice to investigate the teaching effect.

\section{E. Reform of teaching methods for the serial courses of Biomass processing and utilization}

With the continuous development of higher education, the requirements for quality and levels in the teaching of bioengineering were also changed, so it was necessary to perform teaching reform and promote the cultivation effect for the students. To satisfy the talents cultivation requirements, biolengineering major teaching should based on innovation training to develope comprehensive abilities of student. The effective way was to implement teaching reform.

The reform of biomass material processing and utilization courses was an attempt to adapt the cultivate aim of biogengineering major to meet social needs and expand students' future employment field. The practice emphasized the central role of students in the teaching process and took students as the main body, which stimulated students' subjective initiative in the learning process and improved the teaching effect[5,6].The aims of Biomass materials course for bioengineering major in agricultural colleges and universities were to explore an efficient teaching way for cultivating 
excellent specialized talents for the society, and to practice the teaching content and teaching method to meet the social needs.

In the process of classroom teaching, students were assigned with course-related homework. The students were divided into groups to prepare report materials, and representatives from each group were sent to the platform to give lectures for other students. They introduced relevant course knowledge, improved students' participation in class, and stimulated students' enthusiasm for learning. They were guided to establish course interest groups with the theme of comprehensive utilization of biomass materials [7]. According to students' concerns, they set up topics freely and focused on the collection and arrangement of project materials to form special topics, gave them opportunities to show themselves in class, inspired students' interest in learning and improved the teaching effect.

\section{INVESTIGATION OF COURSE TEACHING EFFECT}

In order to further improve the teaching quality and fully understand the teaching effects of the multimedia courseware on the Biomass processing and utilization, we adopted the multimedia teaching method among the students of bioengineering from grade 2014 and 2015, and conducted follow-up survey on the teaching effect. 155 questionnaires obtained. The survey results were shown in TABLE I.

TABLE I. QUESTIONNAIRE ON EFFECT OF MULTIMEDIA COURSEWARE FOR BIOMASS PROCESSING AND UTILIZATION

\begin{tabular}{|c|c|c|c|c|c|}
\hline \multicolumn{3}{|c|}{ Visual effect } & \multicolumn{3}{|c|}{ Auditory effect } \\
\hline Clear & $\begin{array}{l}\text { Fairly } \\
\text { clear }\end{array}$ & Unclear & Clear & Fairly clear & Unclear \\
\hline $65.3 \%$ & $33.6 \%$ & $1.1 \%$ & $74.5 \%$ & $24.2 \%$ & $1.3 \%$ \\
\hline \multicolumn{3}{|c|}{ Proportion of taking notes } & \multicolumn{3}{|c|}{ Feeling of teaching course } \\
\hline $\begin{array}{c}\text { Taking } \\
\text { notes }\end{array}$ & $\begin{array}{c}\text { Partly } \\
\text { notes }\end{array}$ & $\begin{array}{c}\text { No } \\
\text { note }\end{array}$ & Impressive & $\begin{array}{c}\text { Same to } \\
\text { conventional } \\
\text { way }\end{array}$ & Unimpressive \\
\hline $9.9 \%$ & $67 \%$ & $23.1 \%$ & $47.7 \%$ & $20.4 \%$ & $31.9 \%$ \\
\hline \multicolumn{3}{|c|}{ Preview proportion of students } & \multicolumn{3}{|c|}{ Review proportion of students } \\
\hline Fully & Sometime & None & Immediately & Sometime & None \\
\hline $30.8 \%$ & $59.6 \%$ & $9.6 \%$ & $41.5 \%$ & $49.7 \%$ & $8.8 \%$ \\
\hline \multicolumn{3}{|c|}{ Adaption to multimedia } & \multicolumn{3}{|c|}{ Comment on multimedia } \\
\hline Quickly & Gradually & No & Very good & Good & General \\
\hline $30.7 \%$ & $61.5 \%$ & $7.8 \%$ & $58.5 \%$ & $31.9 \%$ & $9.6 \%$ \\
\hline
\end{tabular}

The results showed that the majority of students accepted the multimedia courseware of Biomass processing and utilization and supported the development of multimedia courseware of Biomass processing and utilization. By analyzing students' views, opinions and suggestions on the multimedia teaching of course, we concluded that most students have the following views:

$a$. The multimedia teaching form of Biomass processing and utilization was novel and vividly, which can mobilize desire of course content of students in class. b. Multimedia teaching saved handwriting time on blackboard for teachers and improved teaching efficiency.

c. The teaching courseware was consisted with text and pictures, which could attract attention of students, have good audio-visual effects and would deepen memories for students.

$d$. The courseware was easy to duplicate, it was convenient for students to review.

\section{CONCLUSION}

In the research, it was found that although the establishments of Biomass series courses meet the teaching needs of biological engineering major in agricultural colleges and universities. However, the social demands for talents in biomass materials development and processing were more than the knowledge from book in this field. The technicians also required to have comprehensive understanding of theoretical and processing on biomass-related materials. Therefore, it is necessary for the teacher to pay more attention to the supporting courses for biomass, i.e. organic chemistry, analytical chemistry, biological chemistry etc. A teaching system with broad principle and practice in the courses should be established in the future. In the process of revising the talent training program, we should strengthen the development of relevant courses.

\section{ACKNOWLEDGMENT}

The authors are grateful for the supports of Professor Jianfeng Zhang, Xue-jun Zhu and other colleagues from Jilin Agricultural University in collection of teaching materials, development of multimedia courseware, and teaching reform practice.

\section{REFERENCES}

[1] J.C. Wang, L. Dai, Y.S. Tian, et al. Current situation and trend analysis of biomass energy industry in China. Journal of Agricultural Engineering, 2007, 23 (9): 276-282. (In Chinese)

[2] C. Chang, P.Q Sun, S.H Sun, et al. Prospect of modern application of biomass energy in China (ii) -- conversion approach of biomass to liquid fuel. Chinese and Foreign Energy, 2014, 7:16-24. (In Chinese)

[3] N.L. Zheng. Chinese "13th five-year" on biomass energy development strategy. Petroleum Refinery and Chemical Industry, 2015, 46: 56. (In Chinese)

[4] L.J. Weng. Technical status and development of biomass power generation. Building Materials and Decoration, 2016, 1:237-238. (In Chinese)

[5] X.H. Liu, S.Y. Fu. An analysis of teaching philosophy and teaching methods of biomass energy technology. Science and Education, 2016, 342:60-61.(In Chinese)

[6] M.G. Ma, J.X. Jiang. Teaching reform of principles and technologies of biomass energy utilization. China Forestry Education, 2009, 27 (4): 64 67. (In Chinese)

[7] J. Li, J.L. Zheng, Q. Wei, et al. Exploration of teaching reform in biomass energy engineering and technology. Guangzhou Chemical Industry, 2015, 43 (19): 226-228. (In Chinese) 